\title{
Experiences from the Process of Designing Lessons with Interactive Whiteboard: ASSURE as a Road Map
}

\author{
Bahar Baran \\ Dokuz Eylul University, Turkey
}

\begin{abstract}
This study investigates university level students' experiences of designing lessons with an interactive whiteboard as an instructional medium. The sample consisted of 40 students who will be both moderator of technological resources in schools and computer teachers after graduation from university. In the design of a lesson process, the ASSURE instructional design model was their roadmap. The results showed that none of the students had used interactive whiteboards before the course. However, most of them knew interactive whiteboards from other courses, seminars, or the Internet. Nearly half of the participants had some hesitations when they first learned that they were going to use interactive whiteboards in the course. After using it during a lesson, however, their opinions became positive. In addition, ASSURE instructional design model let them to progress systematically and step-by-step. Most of them had problems to find educational software to use with interactive white board. That is, their primary problem was with the "select instructional methods, media, and materials" step of the ASSURE model.
\end{abstract}

Keywords: Interactive whiteboard; Instructional design; ASSURE; Technology integration

\section{Introduction}

The Trends in International Mathematics and Science Study (TIMSS, 1999, 2003, 2007) "provides reliable and timely data on mathematics and science achievement" in many countries. TIMSS showed that Turkish elementary school students scored low in both mathematics and science. Twenty-nine of the forty-nine countries examined had mathematics scores that were significantly higher than Turkey's, and thirty countries had science scores that were significantly higher than Turkey's (Kaplan, 2009; TIMSS, 2009). Therefore, improving student achievement has recently become the focus of the Ministry of National Education and Turkish academicians. Of course, there may be different reasons for this low achievement. However, the idea of using innovative technologies, which make abstract concepts more concrete and increase motivation, to develop students' mathematics and science abilities is one of the most widely accepted solutions (Somyurek, Atasoy, \& Ozdemir, 2009).

For years, educators have tried to integrate technology into the classroom with the aim of furthering science and math achievement. In the past, printed material, audiovisual media, and calculators were seen as the primary solutions to learning problems. These technologies may have a positive effect on learning. If so, though, why have teachers in Turkey not used them effectively? The answer may be related to lack of technology integration in the classroom and research problems. Today, the interactive whiteboard (IWB) is a novel and attractive technological advancement for the Turkish teachers. There has recently been considerable 
investment in the installation of IWBs in Turkish public schools. This new technology now needs to be seamlessly integrated into classrooms.

\section{IWB in the Classrooms}

IWB technology includes three elements: a digital board, a computer, and a projector. A personal computer is linked to both the board and the projector. Therefore, the interactive board differs from a regular board because it receives input from a computer in addition to direct handwriting. Software has been produced for IWBs in order to make them easier to use. Through the link with a computer, the board is projected onto the screen of the computer. The board is then able to present students with the regular attributes of computers, such graphic tools, word processors, spreadsheet tools, database tools, and multimedia tools. In addition, the development and widespread use of the Internet has made IWBs seem like indispensable technological tools for teachers. IWBs enable teachers to use social networking technologies such as Listserv, Wiki, Facebook, Twitter, etc.

Many research studies have suggested that interactive whiteboards improve students' achievement (Dill, 2008; Jones, 2004; Thompson \& Flecknoe, 2000). In addition, interactive whiteboards raise student motivation in the classroom (Smith, Hardman, \& Higgins, 2006). These findings highlight the importance of using interactive whiteboards in education. When compared with other countries, teachers in Turkey have recently started to use it. Besides, Turkey has limited research on the technical and pedagogical use of the boards, teachers' professional development, and student motivation and achievement (Higgins, Beauchamp, \& Miller, 2007).

Ozdemir and Kilic (2007) identified the problems with Information and Communication Technologies (ICT) integration in Turkey. These are: (1) the inadequate attention paid to the professional, organizational, and cultural changes needed to realize the project's goals; (2) the consequent lack of time, funding, and resources for working through the development process; (3) the emphasis on technology rather than on pedagogy; (4) the inadequate knowledge and skills of the administrators, inspectors, computer coordinators, and classroom teachers; (5) the lack of monitoring and timely identification and resolution of problems; and (6) underlying all of these issues, a lack of leadership and strategic direction (p. 913). Similarly, a meta-analysis of 20 years of key policy reports addressed the challenges and opportunities in integrating technology with teaching and indicated the following recommendations aimed at supporting and sustaining investments (Culp, Honey, \& Mandinach, 2005, p.286-287):

- Improve access, connectivity, and requisite infrastructure;

- Create more high-quality content and software;

- Provide more sustained, high-quality professional development and overall support for teachers seeking innovation and growth in this domain;

- Increase funding from multiple sources for a range of relevant activities;

- Define and promote the roles of multiple stakeholders, including the public and private sectors;

- Increase and diversify research, evaluation, and assessment; and

- Review, revise, and update regulations and policies that affect the use of technology, particularly those regarding privacy and security. 
As stated above, successful implementation of interactive whiteboards in school environments requires successful leadership and appropriate training opportunities (Glover, Miller, Averis, \& Door, 2004). Miller and Glover (2005) state that implementation success depends on an instructor's ability to improve pedagogy in a timely manner. Therefore, agents of change in the elementary schools, the sample of this study, should have a deeper technological and pedagogical understanding of interactive whiteboards in order to help math and science teachers develop their instructional techniques. This study was based on professional development of students in the Department of Computer Education and Instructional Technology as they pertain to the IWB integration process in elementary schools. In order to take a different analytical approach, this study used the ASSURE instructional design (ID) model to guide students on their way to designing lessons with IWB.

\section{The ASSURE Model}

Instructional design models were classified as classroom oriented, product oriented and system oriented (Gustafson \& Branch, 2002). This study used ASSURE instructional design model which is one of the classroom-oriented models. The main reason of preferring this model is that it is frequently used by teachers in schools because it is for a few hours of instruction and for each individual. In addition, this model does not require high complexity of delivered media, deep ID knowledge, and high revision of designs (Gustafson \& Branch, 2002). The main difference between an inexperienced teacher and an expert teacher is that an expert teacher can easily decide on content, appropriate teaching strategies, and delivery medium. The ASSURE model gives new teachers a general roadmap to follow to help them think more like experts. ASSURE stands for:

- Analyze learners;

- State objectives;

- Select instructional methods, media, and materials;

- Utilize media and material;

- Require learner participation;

- Evaluate and revise.

The "analyze learners" component emphasizes the importance of analyzing learners' entry characteristics, general characteristics, and learning styles. "State objectives" relates to the outcomes of instruction. A teacher should determine the objectives in the second step of the design. "Select methods, media and materials" means that teachers should select appropriate methods, media and materials instead of developing them. In the "utilize media and material" step, teachers should develop an implementation plan to use media and materials effectively. "Require learner participation" means that teachers should try to keep students active during instruction. Finally, "evaluate and revise" refers to the evaluation of teaching and achievement (Heinich, Molenda, Russell, \& Smaldino, 1999).

\section{The purpose of the study}

In sum, the IWB has been a novel teaching tool of great interest in the classroom environment for a few decades. Educators expect that when teachers use a certain technology in the classroom, they use various applications and teaching methods. They should change their teaching style from being lecture-driven to being student-centered. In this way, the technology 
integration process is very important for a teacher's professional development. Therefore, this study aimed to contribute knowledge of professional development on technology integration in classrooms, specifically, learning how to adapt IWB to lessons. More specifically, this study aims to investigate the first experiences of students using IWB as a teaching medium and designing lessons based on the ASSURE model.

\section{Methodology}

\section{The context}

This study was conducted during a 12-week-long course (entitled "Instructional Design") in the Buca Faculty of Education at Dokuz Eylul University in Turkey during the Spring 2009 term. The researcher in this study is also the instructor of the course. This course is required for students in the Department of Computer Education and Instructional Technologies. The course aims to teach the basic steps of designing a lesson. The students followed the main steps of ASSURE instructional design model to design a lesson. A midterm, participation quality and quantity in online discussions, and a term project were used for evaluation of students' performance.

This study is related to the term project part of the course. The topic of the term project was "Designing a lesson from the science or math curriculum by using an interactive whiteboard (IWB)". The instructor suggested that the students use ASSURE as an instructional design model. The aim of this project was to develop participants' instructional design abilities. The projects were group-based and the participants were divided into groups of 3-4 students. The students formed their own groups. Each group presented their project at the end of the term (Figure 1). They began by introducing the project report then proceeded to teach their peers as if they were in a real classroom.

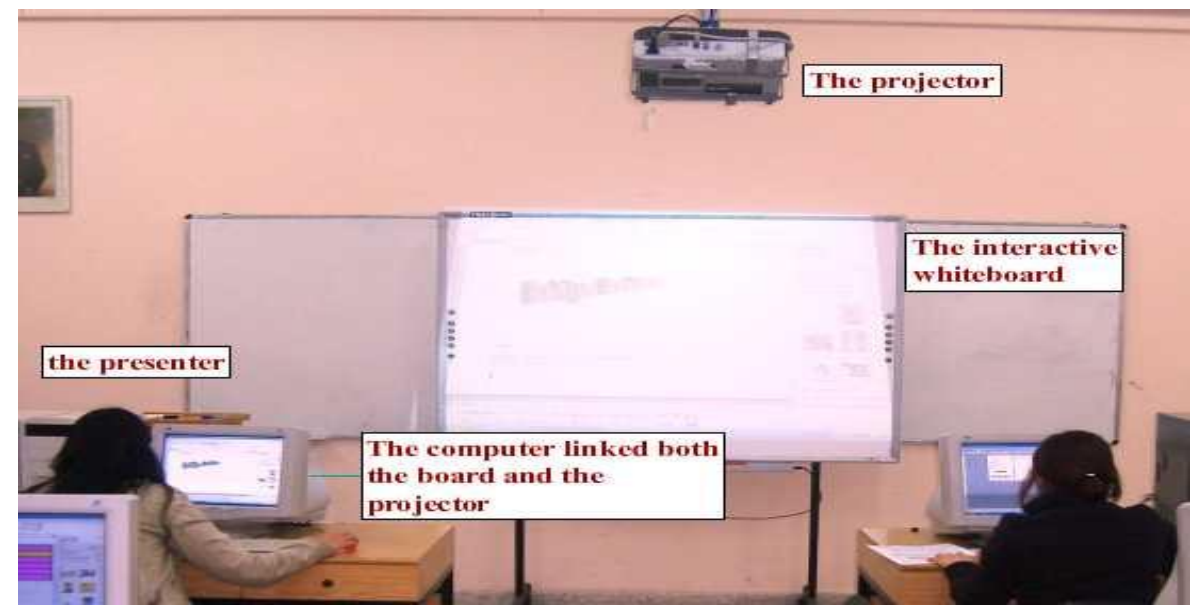

Figure 1. The Interactive whiteboard in the laboratory

\section{Interactive Whiteboard}

The medium of this study was an interactive whiteboard produced by the TraceBoard firm. The main buttons on the board are the pen, rubber, left and right mouse buttons, screen capture, 
screen keyboard, position setting, floating tools, magnification, screen shade, and spotlight (Figure 1). The board has been bought by the department one year before this study.

\section{The Sample}

The sample of this study was comprised of 40 students from the Department of Computer Education and Instructional Technologies. After graduation from the department, they will be both moderator of technological resources in schools and computer teachers. Therefore, the future role of these students is important in technology integration to classes in elementary schools of Turkey. Their knowledge and expertise directly influence the school's technology uses. There were 13 female and 27 male students. Thirty-six of them were sophomores. The remaining four students were juniors and seniors who had failed in the last year.

The participants had not used the interactive whiteboard in none of previous departmental courses. That is, none of them knew how to use it. The students who were retaking the course also did not know the interactive whiteboard since the department had not have the board a year ago. Their background related to instructional design theory was also limited. They have taken following departmental courses which can affect the results of the study: Information Technology in Education, Introduction to Teaching Profession, Preparing Instructional Material, and Development and Learning.

\section{Data Collection and Data Analysis}

The data were collected through written questionnaires, face-to-face interviews, observations, and the students' project reports. The written questionnaires included 13 open-ended questions. Each question had a simple answer choice and then a blank space for detailed explanations. For example: "Have you used IWB in the past? a) Yes, b) No. If yes, where?" The researcher collected all participants' responses in the last course of the term. In addition, she conducted three interviews with three of students. One of these interviewees was a member of a successful group who designed the best lesson. Second interviewee was again an active student. However, the third was a quiet member of a group, who was not so willing to use the interactive whiteboard. Finally, the researcher tried to obtain the best data from these interviewees. The interviews were recorded through a voice recorder. The Interviewees were selected from among willing and informative participants. The researcher observed presenters' IWB usage and the others' participations to the designed lesson during project presentations. These data were collected by taking notes.

Data analysis began with the examination of the written reports produced by each of the students. The researcher analyzed each questions separately. After general themes and codes were defined, each code was counted and related themes became the headings of the article and codes showed the results. Then, interviews were transcribed. Finally, the results were compared with data from the interviews and observation notes.

\section{Trustworthiness}

In the design of a qualitative study, the analysis of the results, and the judgment of the quality of research, the most important issue is trustworthiness (Creswell 1998). To establish the 
trustworthiness of this study, the following strategies were used in accordance with some of the researchers' proposals (Creswell, 1998; Creswell \& Miller, 2000; Golafshani, 2003). First, data collection and analysis were explained in detail in order to inform other researchers about the procedures. Second, written questionnaires transformed to digital format by a word processing; interview data were recorded through a voice recorder. Third, the researcher was present at the research site for a long period of time since she was also the instructor for the course. Due to repeated access to the site, the researcher believed that she established trust with the participants. Fourth, the researcher informed the students that their comments, ideas, beliefs did not influence their course grade. Lastly, different data collection tools were used (as explained above) to assure triangulation.

\section{Findings}

\section{IWB Familiarity}

Two questions were asked in order to determine the participants' familiarity with IWBs. The questions were: "Have you used IWB in the past?" and "Did you hear about IWB before this course?" The results showed that none of the participants had any previous experience using IWBs and that $63 \%$ of them already knew about IWBs (Figure 2). After asking them how they heard about this technology, the following results were obtained: 8 learned about IWB from another course, 8 learned about it at a seminar, 6 read about it on the Internet, and 3 watched a video on Facebook.

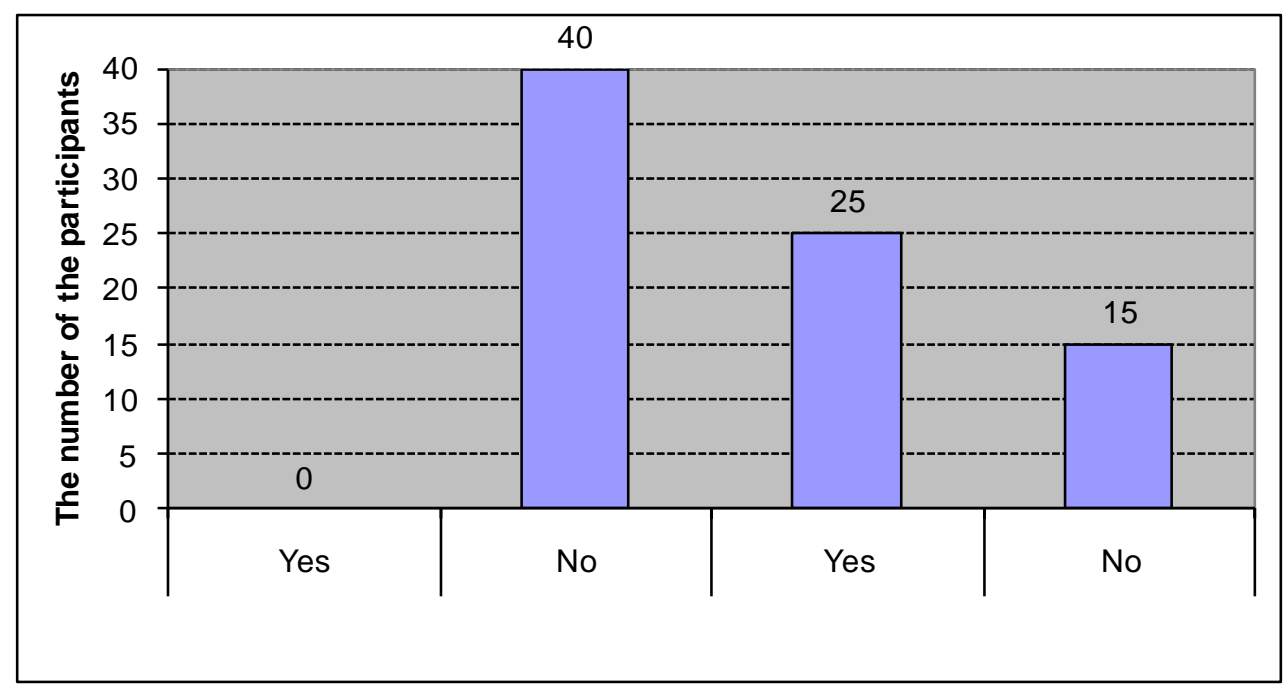

Figure 2. IWB familiarity reported by the participants

\section{Initial Feelings and Changing Opinions}

Initial feelings and changing opinions were investigated by asking two questions: "What did you think when you first learned to use IWB in this course?" and "How did your opinions change after you completed your project?" One of the interviewee explained her class atmosphere when they first learned to use IWB in this course as follows: 
"In the beginning of the term, we should have been stressful since we learned that we should use interactive whiteboard. It was very demanding to know how to use a new technological tool. We could not predict what we would face with while we use it. Maybe, we would not be able to use it..."

Coding schema showed that twenty-one of the forty participants had positive attitudes toward IWB when they learned to use it in this course. However, the other 19 participants had some hesitations and fears about IWB (Figure 2). The participants gave detailed explanations about their initial feelings. Twelve participants demonstrated a willingness to discover new technology. Ten participants stated that IWB would not be easy to use. An additional five participants indicated that they had to learn how to use it because it would be a part of their profession. Were they not to learn how to use IWB, they would encounter serious problems in their schools after graduation. Lastly, four participants indicated that they had a negative bias toward IWB. One of the participants said:

"As a technology teacher, we have to be open to adapt to new technologies. Our profession is a developing and improving field. It is not similar to other fields, such as physics, mathematics, etc."

After becoming experienced with IWB through the course, eighteen of the nineteen participants with negative feelings changed their opinions and became positive about the use of this new technology. Surprisingly, two participants developed new hesitations after the course (Figure 3). To explain their reservations, the students mentioned IWBs calibration problems and the fact that using IWBs in classrooms took more time than regular boards. According to interviews and observations, five participants encountered calibration problems. Calibration of IWB is highly important in ensuring that it is used effectively. If the IWB is not calibrated properly, anything the user tries to write on the board will appear a few centimeters away from its intended location. Regarding the issue of taking more time, three interviewees stated that it was due to their own limited technological abilities. Otherwise, they stated, IWB would not be different from the other boards. One of the interviewee stated:

"IWB use in the course was very different for us. A few friends do not draw straight line because they do not sufficiently press the board maker on the board. Or they forgot to calibrate the board. To me, IWB use was very easy. Most of them also think so. In the beginning our fear was unnecessary"

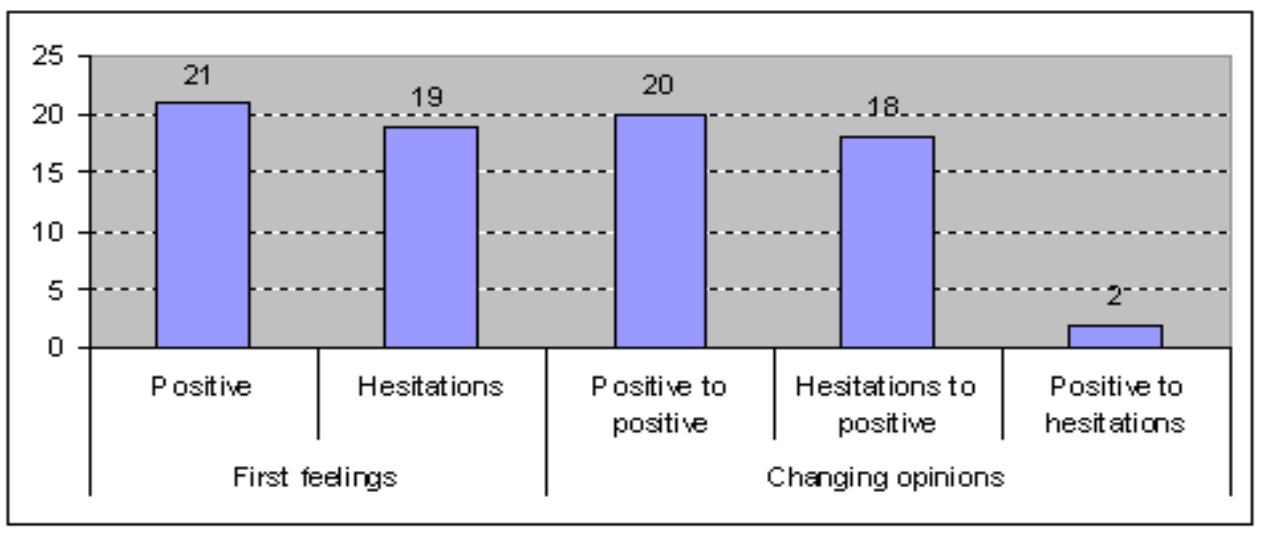

Figure 3. Initial feelings and changing opinions over the course of the study 


\section{IWB Usage in Elementary Schools}

The participants' thought about IWB usage in elementary schools is very important since the participants have a big role of technology integration to their schools after graduation. Written reports showed that thirty-seven of the forty participants suggested using IWB in elementary schools (Figure 4). When asked to explain why they would like to use IWB at the elementary level, the following views were expressed: IWB would increase motivation and interest in lessons ( $N=26)$; IWB would allow for more student participation ( $N=12)$; IWB could make abstract topics more concrete $(N=8)$; IWB would save time $(N=6)$; IWB could make teaching more effective ( $N=7)$; and IWB would make it easy to do experiments $(N=5)$. In addition, one participant stated that IWB had an element of novelty that would make it very effective when used for the first time. It was also mentioned that IWB could prevent teachers from having to turn their backs to students. Two of the participants said:

The board will be beneficial for students. For example, we used a simulation software with the interactive whiteboard. Simulations are important for teaching abstract topics to students. As another advantage, we can easily manipulate the simulation on the board.

Owing to the board, teachers can use interactive software in their classes. So their students' motivation will be high. In addition, students will like to pay attention to the lesson.

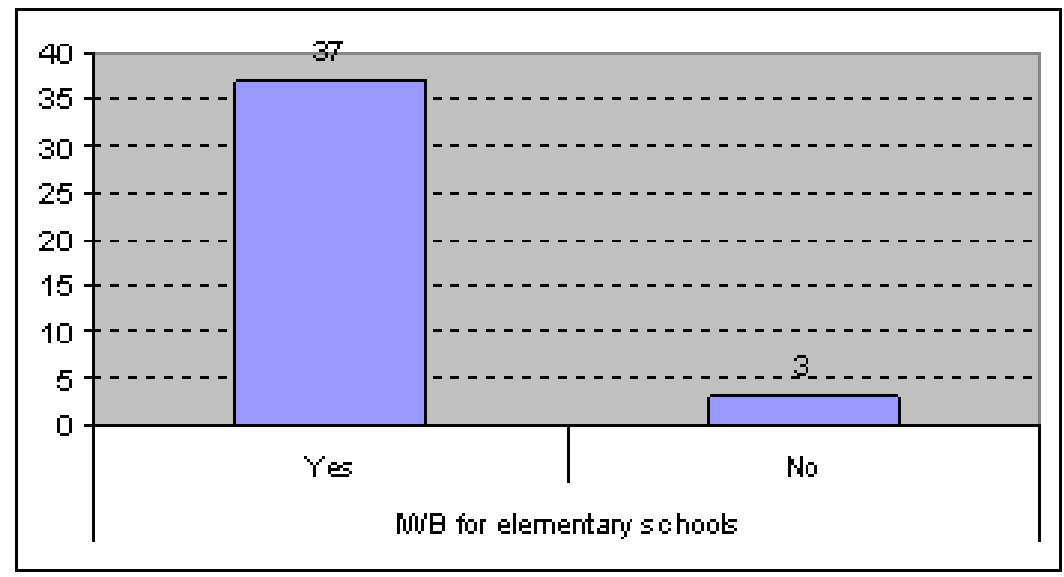

Figure 4. Recommendations for IWB usage in schools by participants

Limitations to IWB use in classrooms were also investigated. Fifteen participants pointed out that some teachers did not know how to use a computer, projector, or IWB. Therefore, the participants believed that these teachers would experience many technical problems. Another important limitation was that IWB required preliminary work before the lesson (mentioned by eight participants). Teachers would need to search for software or small animations to use with IWB, causing their workload to increase. In addition, IWB required buying a computer and a projector, which would create a fiscal burden (mentioned by eight participants). Finally, some participants believed that students could break the IWB if they did not know how to use it (mentioned by five participants). For instance, they could draw on it with the wrong pen. One of them said: 
In the context of Turkey, teachers are very passive to know and use a new technology. For example, we went a school to complete evaluation step of our project. The interactive whiteboard is in a locked room. Nobody knows how to use it. These are very important barriers. So, it is important that teachers are familiar with this technology.

\section{IWB or Blackboard}

The participants compared a traditional blackboard with an IWB and stated the positive aspects of IWB. According to fifteen participants, IWB was more visual and user-friendly. A teacher could use different colors, easily draw geometric figures, create other drawings, or write on projected animations. In addition, IWB was healthier since it would not create dust (mentioned by 10 participants). Finally, IWB provided interactive learning environments (indicated by five participants). According to one participant:

Teachers spend more time writing on the blackboard than being on the IWB. They write, draw, erase, and then, rewrite, redraw...etc. At the end of a lot of tries, they can obtain true figures. Therefore, teachers cannot speak with their students while they are busy with writing. In forty minutes, trying all of them, teaching and paying attention to students is not an easy job. IWB can handle this.

\section{IWB Usage Types}

The results indicated that the groups used different IWB teaching strategies in their 40-minute project lessons. Their IWB usage types were classified according to the data from their written reports and project reports. Ten out of twelve groups used PowerPoint as part of their presentation. Five groups showed special animations in PowerPoint presentations. Five groups used PowerPoint to present scientific knowledge and talk about it. In addition to PowerPoint, 10 groups preferred to select and use other available software. Software used included Phet simulation, Crocodile Math, and Crocodile Physics. Three groups produced animations using Flash and their own animations. Only one group preferred to create handmade material to support their instruction.

Table 1. Characteristics of the three successful designs

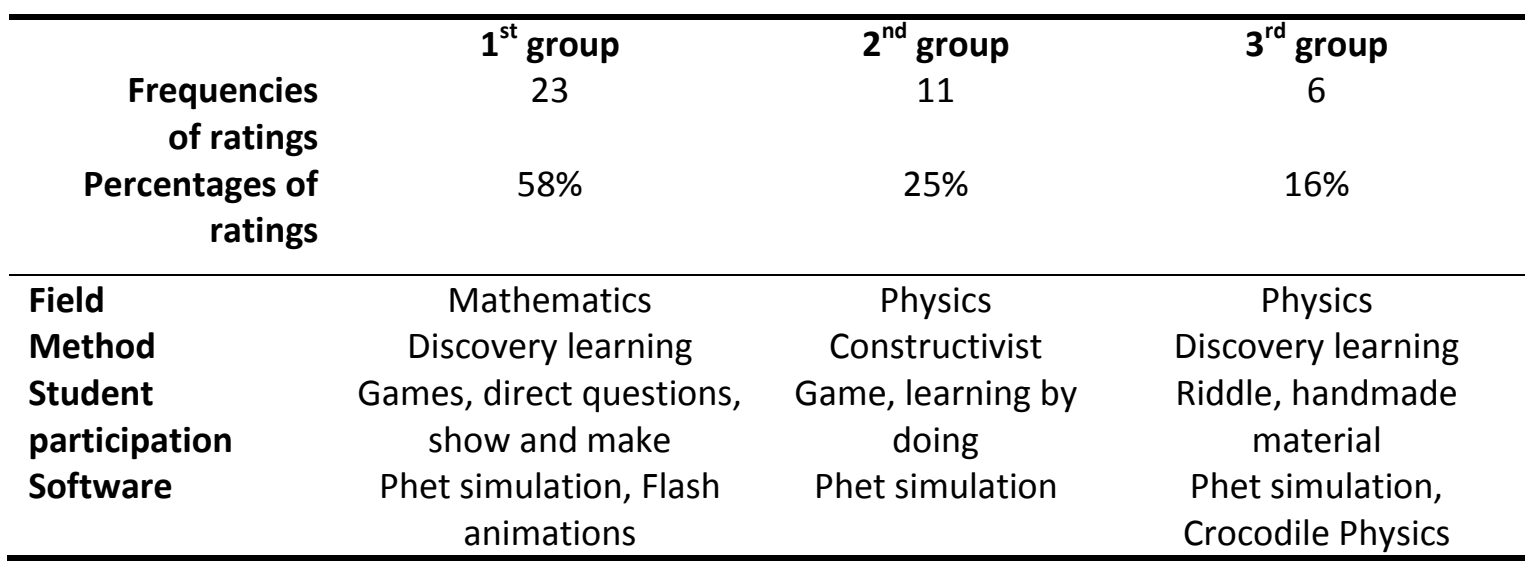


When participants were asked which group prepared/delivered the best presentation, three of the groups were found to be popular. These groups used games as a strategy for increasing student participation. They projected a game onto the IWB and allowed students to play on the board. In the geometry lesson, for example, the students tried to find a complementary angle in a limited period of time in order to earn extra points. Another strategy involved using riddles and having students discuss the answers. In addition, the presenters asked direct questions to the students. Interestingly, only the first group used learning material developed with Flash software. The interviewees stated that the learning material presented by the first group was very attractive and suitable for their topic.

\section{The Design Process Using ASSURE}

The participants were asked how the ASSURE instructional design model affected their teaching. Twenty-four of the forty participants stated that the ASSURE model was a roadmap allowing them to progress systematically and step-by-step. One participant stated:

"The most important contribution of the model was that it showed us which steps we should follow. If we did not use a model we would start with the select media step. This decision would negatively affect our design."

Another participant stated:

"We think using IWB without the ASSURE model would be a disappointment. The ASSURE model was a route that indicated to us how a medium and a material can be used effectively."

Eight of the forty participants emphasized the importance of analyzing learners before creating a design. This first step of the ASSURE model improved the quality of teaching. The final eight participants stated that ASSURE allowed them to design more interactive environments since the model drew attention to learner participation.

In addition, participants reported difficulties with instructional design in which IWB was the medium of instruction. They stated that their main problem was with the "select instructional methods, media, and materials" step of the ASSURE model (mentioned by 16 participants). In particular, they reported having difficulty selecting the appropriate IWB software that would make teaching more visual, interactive, and entertaining. In addition, 13 participants stated that they had difficulties with the "utilize media and materials" step of the ASSURE model. They faced technical problems while using IWB due to their lack of experience. Lastly, four participants stated that the "analyze learners" step of the ASSURE model was very challenging. They specifically had trouble finding Turkish assessment inventories to apply students

The last question related to the use of the ASSURE model stated, "Will you use the model after graduation, and why?" Thirty-one of the forty participants said "Yes". These participants emphasized that the ASSURE model forced them to plan, work systematically, and ensure quality. Six participants responded, "I do not know". These participants did not make any comments because they did not believe they were knowledgeable enough in this field. The final four participants answered "No". These participants stated that they did not want to be instructional designers; instead, their aim was to become computer programmers. 


\section{Motivators in the Design of a Lesson}

Participants evaluated the factors that motivated them while designing their lessons. The results show that most participants were motivated because they believed the advantages of IWB. Their first experience with IWB became another motivator. In addition, IWB's connection to their profession was also very important. Finally, good group work and obligation were two additional motivators.

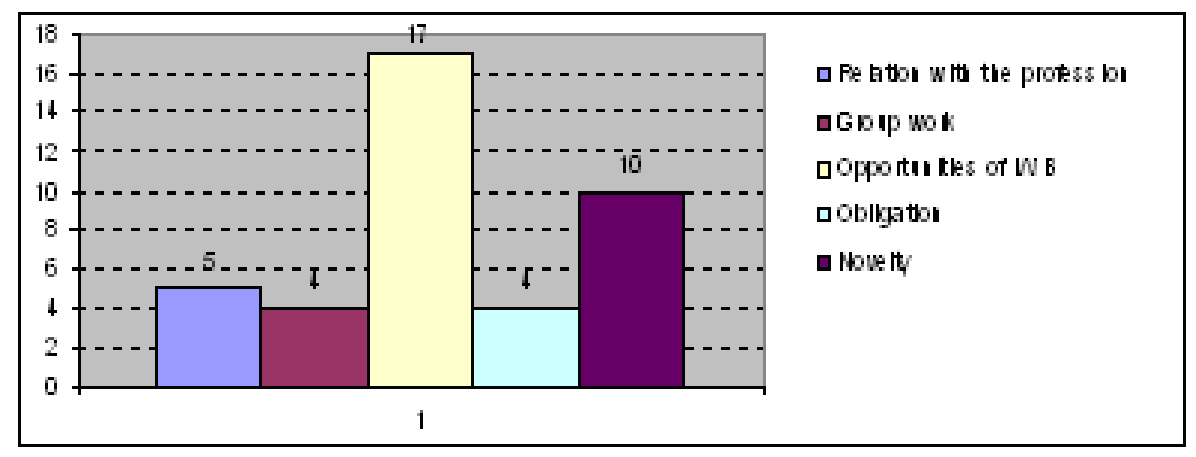

Figure 5. Motivators in the design of a lesson

\section{Discussion and Conclusion}

The first finding pertains to IWB familiarity. None of the participants had used interactive whiteboards before taking the course. However, most of them heard about IWBs from other courses, seminars, or the Internet. In addition, nearly half of the participants had some hesitations and fears when they first learned to use the boards. Yet after using them to teach a lesson, their opinions became positive. Somyurek, Atasoy, and Ozdemir (2009) revealed that $36 \%$ of current teachers used IWB in their schools. In addition, most of these teachers did not have a fear of this technology. These results show that teachers, both pre-service and current, had hesitations and fears when faced with an unknown educational medium. Therefore, professional development is the most important factor to consider before forcing teachers to use new technology in their classroom activities (Culp, Honey \& Mandinach, 2005; Glover, Miller, Averis, \& Door, 2004; Ozdemir \& Kilic, 2007). Furthermore, if teachers learn to utilize this technology as a part of their teaching life instead of only learning how to work it, their attitudes will be more positive and they will apply it more successfully. In addition, the most important part influencing the quality of a lesson, in which IWB is used, is "pedagogical background rather than only technology" as said by Ozdemir and Kilic (2007). Therefore, professional development of teachers should be an ongoing process supporting both technology usage and pedagogical knowledge (Culp, Honey \& Mandinach, 2005). Furthermore, participants in this study supported the use of IWB in elementary schools because they believed that it increased motivation, interest, student participation, and concreteness of abstract concepts. This finding could be accepted as a positive indicator to use this technology in schools.

The findings indicate that the two most difficult steps in the ASSURE model are "select methods, media, and materials" along with "utilize media and materials". The results of the 
present study suggest that the participants experienced some difficulties in finding educational software and deciding which titles would add to their lessons. Although IWBs have their own software to assist users, they do not have field-specific solutions for teachers. Therefore, teachers need to have access to science or math animations, experiments, or videos because developing new materials would be a very demanding task (Culp, Honey \& Mandinach, 2005). A lack of IWB educational software may cause resistance to IWB use in teaching. Therefore, teachers' professional development studies should focus on how they can find educational materials that can be used with IWB.

Participants in this study generally preferred to use PowerPoint with IWB. At times, they talked on PowerPoint or used it to show animations. Previous research has indicated that PowerPoint sometimes discourages complex thinking and therefore negatively affects learning. On the other hand, it can also encourage attention and therefore positively affect learning (Bartsch \& Cobern, 2003; Reedy, 2008). In addition, teachers and students conflated IWB technology with PowerPoint in their minds, regardless of whether ICT adopters accepted them separately (Reedy, 2008). Therefore, it should be known that teachers' first software preference for use with IWB will likely be PowerPoint. PowerPoint is easy to access and easy to use to prepare animations. As a result, teachers should know how to use it effectively in their teaching.

Theoretically, we hope to improve learning by increasing interaction. According to the results of the present study, increasing student interaction made an IWB lesson more effective. The most preferred teaching designs in this study emphasized student participation, which is also an important part of the ASSURE instructional design model. Games or animations were some of the strategies used to foster interactivity. Higgins, Beaucamp, and Miller (2007) separate the technical and pedagogical IWB interactivity in the literature. Technical interactivity refers to teachers' or students' manipulation of IWB. Pedagogical interactivity involves efficient teacherstudent and student-student interaction (Smith, Hardman \& Higgins, 2006). Decreased technical interactivity increases pedagogical interactivity, and the reverse is also true. Kelley et al. (2007) discussed teachers' ineffective interactivity strategies. To them, first, encouraging all students to become involved with IWB is time-consuming, if not totally impossible. Second, every student will not be eager to stand up in front of the board. Therefore, wireless mice and keyboards can be used. As a summary, related to interaction, present study proposes that teachers should ensure of providing both technical interactivity and pedagogical interactivity in their lessons.

The mission of the Department of Computer Education and Instructional Technologies has been discussed for a long time in Turkey (Ozbay, 2005). Graduates of this department become both computer teachers and instructional technologists. The results of this study indicate that the participants accepted new technological adaptations as a part of their profession. This acceptance has been an important motivator in the technology integration process. Therefore, if trained properly for their prospective roles, graduates of the department can be agents of change in schools.

In conclusion, this study aimed to contribute to the limited literature on IWB integration in Turkish schools. The study investigated students' familiarity, initial feelings, changing opinions, views on IWB usage in elementary schools, difficulties in the design of lessons, and motivators for teaching. Due to the importance of technology integration to lessons, more research along these lines is required in the future. 


\section{References}

Bartsch, R. A. \& Cobern, K. M. (2003). Effectiveness of PowerPoint presentations in lectures. Computers and Education, 41(1), 77-86.

Berry, R. Q., Reed, P. A., Ritz, J. M., Lin, C. Y., Hsiung, S., \& Frazier, W. (2005). STEM Initiatives: Stimulating students to improve science and mathematics achievement. The Technology Teacher, 64, 23-29.

Creswell, J. W. (1998). Qualitative inquiry and research design: Choosing among five traditions. New York: Sage.

Creswell, J. W., \& Miller, D. L. (2000). Determining validity in qualitative inquiry. Theory into Practice, 39(3), 124-130.

Culp, K., M., Honey, M., \& Mandinach, E. (2005). A retrospective on twenty years of education technology policy, Journal of Educational Computing Research, 32(3), 279-307.

Glover, D., Miller, D. J., Averis, D., \& Door, V. (2005). Leadership implications of using interactive whiteboards: linking technology and pedagogy in the management of change, Management in Education, 18(5), 27-30.

Golafshani, N. (2003). Understanding reliability and validity in qualitative researches. The Qualitative Report, 8(4), 597-607.

Gustafson, K. L., Branch R. M., \& Maribe R. (2002). Survey of Instructional Development Models (3rd ed.). ERIC Clearinghouse on Information Technology mode, Syracuse, NY.

Heinich, R., Molenda, M., Russell, J. D., \& Smaldino, S. E. (1999). Instructional Media and Technologies for Learning (6th ed.). Upper Saddle River, NJ: Merrill.

Higgins, S., Beauchamp, G., \& Miller, D. (2007). Reviewing the literature on interactive whiteboards. Learning, Media and Technology, 32(3), 213-225.

Jones, S. \& Tanner, H. (2002). Teacher's interpretation of effective whole- class interactive teaching in secondary mathematics classrooms. Educational Studies, 28(3), 265-274.

Kaplan, S. (2009). Turkiye, matematik-fen egitiminde ucuncu ligde. Hurriyet, http://hurarsiv.hurriyet.com.tr/goster/haber.aspx?id=10912455\&tarih=2009-02-03

Kelley, P., Underwood, G., Potter, F., Hunter, J., \& Beveridge, S. (2007). Viewpoints. Learning, Media and Technology, 32(3), 333-347.

Miller, D. \& Glover, D. (2005). Evolution for a revolution: Professional development for mathematics teachers using interactive whiteboard technology. Keele, UK: Keele University.

Ozbay, M. (Ed.) (2005). Egitim fakultelerinde yeniden yapilandirmanin sonuçlari ve ögretmen yetiştirme sempozyumu [The results of reconstruction of faculties of education and teacher training symposium]. Ankara: Gazi Universitesi.

Ozdemir, S., \& Kilic, E. (2007). Integrating information and communication technologies in the Turkish primary school system. British Journal of Educational Technology (BJET), 38(5), 907-916.

Reedy, G. B. (2008). PowerPoint, interactive whiteboards, and the visual culture of technology in schools. Technology, Pedagogy and Education, 17(2), 143-162. 
Smith, F., Hardman, F., \& Higgins, S. (2006). The impact of interactive whiteboards on teacherpupil interaction in the national literacy and numeracy strategies. British Educational Research Journal, 32(3), 443-457.

Somyurek, S., Atasoy, B., \& Ozdemir, S. (2009). Board's IQ: What makes a board smart? Computers and Education, 53, 368-374.

Thompson, J. \& Flecknoe, M. (2000). Raising attainment with an interactive whiteboard in Key Stage 2, MIE, 17(3).

TIMMS (1999). The Trends in International Mathematics and Science Study. Retrieved from http://timss.bc.edu/timss1999i/publications.html

TIMMS (2003). The Trends in International Mathematics and Science Study. Retrieved from http://timss.bc.edu/

TIMMS (2007). The Trends in International Mathematics and Science Study. Retrieved from http://timss.bc.edu/TIMSS2007/mathreport.html

Correspondence: Bahar Baran, Assistant Professor, Department of Computer Education and Instructional Technologies, Buca Faculty of Education, Dokuz Eylul University, Izmir, Turkey. 